\title{
THE EFFECTS OF VARIABLE FACTORS ON CRUSHING STRENGTHS OF DENTAL AMALGAMS
}

\author{
N. O. TAYLOR, Ph.D., W. T. SWEENEY, A.B., D. B. MAHLER, M.S., AND \\ E. J. DINGER, D.D.S. \\ School of Dentistry, University of Michigan, Ann Arbor, Mich.
}

$\mathrm{D}^{\mathrm{s}}$

ENTAL amalgams constitute a most important and very high proportion of individual tooth restorations. The physical properties of finished amalgams, upon which the restorations depend for satisfactory service, vary with the alloy formulas, manufacturing methods, mixing procedures, and condensation technics.

Previous studies of amalgams have established the effects of many variables and the American Dental Association and Federal Specifications for Dental Amalgams have established performance standards which are generally accepted.

In the earlier tentative drafts of these specifications, the physical qualities governed by detailed requirements included setting expansion, flow, and crushing strength. In later revisions the erushing strength requirements were eliminated primarily because those amalgams which met the flow requirements also met the crushing strength requirements. Notwithstanding the discontinuance of this early and rather low requirement, the erushing strength of amalgams under many conditions have been reported in dental literature. ${ }^{1,2,3}$

In considering some problems involved in the selection of testing methods for gypsum products it became apparent that some characteristics of these materials eould best be determined by studying their elastic properties and crushing strengths under loads very slowly applied. As data available on the crushing strengths of amalgams gave no definite indication of the loading rates employed, it appeared of interest to observe the effects of variations in loading rates on amalgams.

An introductory series of tests to determine crushing strengths of amalgams under slow loading indicated that it would be possible to determine both elastic and plastic characteristics of these materials, and so gain some new basic information which could be related to the usefulness of these alloys in service.

After considerations of many of the variables involved in amalgam technies, series of tests were outlined which would show the effects of several individual factors. Those factors which can be controlled by the dentist were given major consideration. In recent years the increasing use of mechanical amalgamators has made their effects of interest; similarly, the effects of mechanical condensing devices are of interest to the dental profession, so these were also ineluded.

In practice, amalgam mixes seldom contain more than twelve grains of alloy plus the required amount of mercury; and as the current amalgamators are

A report of research on dental materials supported by the Office of Naval Research. Received for publication, September 3,1948 . 
not designed to handle larger mixes well, it was decided that a twelve-grain mix would be a closer approximation to the mixes used in dental practice than the large crushing strength specimen used by most previous workers. This size of mix is sufficient to make a cylindrical test specimen $4 \mathrm{~mm}$. in diameter and $8 \mathrm{~mm}$. long, which is the standard A.D.A. specification size for flow test specimens.

Following the selection of the specimen size, tests were outlined to show the variation of crushing strengths for amalgam when: (1) Two sizes of specimens were tested; $6 \times 12 \mathrm{~mm}$. and $4 \times 8 \mathrm{~mm}$.; (2) the loading rate (as measured by head travel of the testing machine) was varied; (3) the method of mixing was varied; (4) the method of condensation was varied; and (5) the age of the specimens when tested was varied.

Five current dental alloys listed below were selected for test.

\begin{tabular}{ll}
\multicolumn{1}{c}{ Alloy } & \multicolumn{1}{c}{ Manufacturer } \\
Aristaloy & Baker \& Company \\
Fine Cut & The L. D. Caulk Company \\
Twentieth Century & The L. D. Caulk Company \\
White Beauty & Lang Dental Mfg. Co. \\
True Dentalloy (A) & The S. S. White Dental Mfg. Co.
\end{tabular}

These include two fine cut alloys, two which would be classed as medium in particle size, and a fifth which would be considered relatively coarse cut. The following details of procedure were established:

1. Test specimens were packed in split steel molds of appropriate dimensions, clamped on the working surface of the pressure recording device developed and previously reported by Ward and Scott ${ }^{1}$ so that it was possible to observe visually the pressure exerted by the condensing instruments.

2. Alloy samples (12 grains) and mercury were weighed on a Crandall balance. The alloy-mercury ratio was $5 / 8$ for all specimens.

3. Mixing procedures were as follows: (A.) "Mortar mixing" indicated that the alloys were mixed in a properly conditioned $\mathrm{S}$. S. White No. 9 mortar in accordance with the manufacturer's directions with the exception that trituration in the mortar was continued until results equivalent to that obtained by mulling (if specified) were obtained. (B.) The term "normal" was used to describe samples mixed in the Rose Amalgamator for time intervals which would provide characteristies in mixes as nearly as it was practically possible to duplicate those obtained by mortar mixing. (C.) Variations in the mixing time in the Rose Amalgamator to provide inadequate mixing were listed as "undermixed," and similarly extended mixing times gave "overmixed." The characteristies of the alloys tested varied markedly and Table I indicates the time intervals associated with these descriptive terms. To obtain uniformity of mixing conditions the amalgamator was operated on 110 volts A.C. Voltage was constantly checked by an indicating voltmeter and controlled by a variable transformer. Time intervals were measured by an electric timer or a stop watch. 
(D.) Mercury from portions of the mixed alloys was expressed through a squeeze cloth by twisting and by finger pressure as required just prior to packing. The mixed amalgam specimens were divided into four to five portions for packing.

TABLE I

Mixing Time in Rose Amalgamator

\begin{tabular}{c|c|c|c}
\hline ALLOY & $\begin{array}{c}\text { ENDERMIX } \\
\text { (SECONDS) }\end{array}$ & $\begin{array}{c}\text { NORMAL } \\
\text { (SECONDS) }\end{array}$ \\
\hline 1 & 5 & 8 & 13 \\
2 & 8 & 13 & 18 \\
3 & 10 & 20 & 20 \\
4 & 15 & 20 & 25 \\
5 & 14 & & 25 \\
\hline
\end{tabular}

4. Condensing procedures were selected as follows: (A.) "Hand" condensation indicates that samples were packed using 6- to 8-pound thrusts on a 2-mm. diameter, smooth-faced plugger stepped around the walls of the cavity and across the center after each addition of alloy until the final surface was reached. Then a 4-mm. diameter smooth-faced plugger was used and pressures increased to aid in the removal of the last excess of mercury. (B.) Specimens packed with the mechanically driven condensor indicated as "A" were prepared using a handpiece speed of 1440 r.p.m. As pressure could be applied through this instrument the terms light, medium, and heavy were used to indicate thrust pressures of 2-4 lbs., 5-6 lbs., and 7-8 lbs. Condensation was started with a plugger $2 \mathrm{~mm}$. in diameter and finished with one $4 \mathrm{~mm}$. in diameter. (C.) Specimens were packed with a mechanically actuated condensor indicated as " $\mathrm{B}$ " which provided a vibratory motion to the packing point when pressures were applied. Investigation showed that even relatively low pressures would stop the vibratory action of the instrument, and so tests were made with it by varying handpiece speeds from 1440 to 2175 and 3250 r.p.m. Pressure as applied to the instrument during these tests was approximately two pounds as shown by the manometer. Condensation was started with a point $2 \mathrm{~mm}$. in diameter and finished with one $3.5 \mathrm{~mm}$. in diameter. (D.) A third series of mechanically condensed specimens was prepared by using an air-actuated, impact type of condensor indicated as " $\mathrm{C}$ " with air valve set at notch 8 (lowest impact notch 1) and with variable compressor speeds later indicated as 3,4 , and 5, and associated with speeds of 640,750 , and 700 r.p.m. when operated on 110 volts. It was noted that the motor speed of this instrument varied greatly with voltage and motor temperatures. The voltage was controlled as described earlier for the amalgamator used, and the motor was operated at least 20 minutes before any test was made in order to increase uniformity of conditions. The straight handpiece of instrument was used with a single condensing point $3.7 \mathrm{~mm}$. in diameter and pressure was applied only until the valve operated (about one to one and one-half pounds).

The variations in speed with time and voltage previously mentioned are large enough to seem worthy of consideration since they constitute a warning of possible inconsistent end results in amalgam work. 
Fig. 1 illustrates the variation in the speed of the compressor used with the length of operating time. It will be noted that both the number and power of impacts produced will vary widely as the motor operates for longer intervals. Table II gives average speeds at the settings indicated after the compressor was operated 20 minutes or more, and again marked differenees in performance are to be observed. (E.) Both ends of all specimens were trimmed smooth with a razor blade before removing from the steel die and while still susceptible to

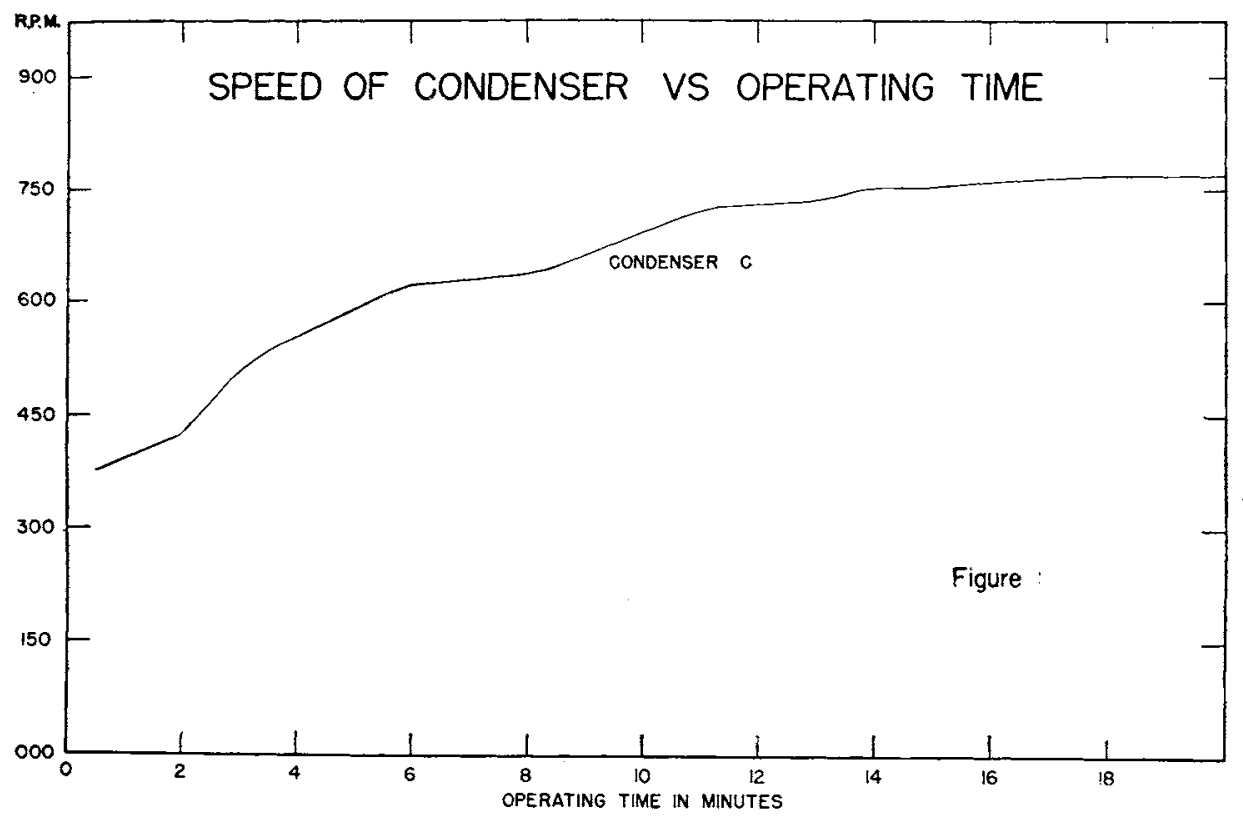

Fig. 1.

carving. Some earlier flow tests on standard alloys indicated little differences in results with specimens so prepared and those whose ends were turned in a lathe. All specimens were prepared and tested at room temperature $\left(22^{\circ}\right.$ to $26^{\circ}$ C.).

TABILE II

Average Variations in Speeds of Compressor "C" with Volitage

\begin{tabular}{c|c|c|c}
\hline SPEED & & \\
SETTING & $105(\mathrm{RPM})$ & $110(\mathrm{RPM})$ & $115(\mathrm{RPM})$ \\
\hline 3 & 550 & 640 & 710 \\
4 & 680 & 750 & 860 \\
5 & 700 & 770 & 875 \\
\hline
\end{tabular}

TEST DATA

Specimens were prepared by various combinations of the mixing and condensing procedures outlined, and the results secured are shown in the following 
tables. Unless otherwise noted the values for erushing strength represent average values for three or more specimens reported to the nearest $100 \mathrm{lbs}$. per square inch. Deviations from the averages were within plus or minus 3 per cent.

\section{TABLE III}

EFfect of Specimen Size on the Crushing Strength of Dental Amalaams

Specimens seven days old-Compressed .003 inch per minute

\begin{tabular}{|c|c|c|c|c|}
\hline \multirow[b]{2}{*}{$A L J, O Y$} & \multirow[b]{2}{*}{ MIX } & \multirow[b]{2}{*}{ CONDENSED BY: } & \multicolumn{2}{|c|}{ SPECIMEN SIZE } \\
\hline & & & $\begin{array}{c}4 \times 8 \text { MM. } \\
\text { (LBS. PER } \\
\text { SQUARE INCH) }\end{array}$ & $\begin{array}{c}6 \times 12 \text { MM. } \\
\text { (LBS. PER } \\
\text { SQUARE INCH) }\end{array}$ \\
\hline $\begin{array}{l}2 \\
3 \\
4\end{array}$ & $\begin{array}{l}\text { Normal } \\
\text { Normal } \\
\text { Normal }\end{array}$ & $\begin{array}{l}\text { Hand } \\
\text { Hand } \\
\text { Hand }\end{array}$ & $\begin{array}{l}34600 \\
39300 \\
37800\end{array}$ & $\begin{array}{l}33700 \\
38500 \\
35300\end{array}$ \\
\hline
\end{tabular}

TABLE IV

Effect of Compression Rate on the Crushing Strengths of Dental Amalgams

Normal mix-Hand packed-4 $48 \mathrm{~mm}$. specimens-seven days old

\begin{tabular}{|c|c|c|c|}
\hline ALLOY & \multicolumn{3}{|c|}{ COMPRESSION RATE } \\
\hline $\begin{array}{l}1 \\
2 \\
3 \\
4 \\
5\end{array}$ & $\begin{array}{l}39500 \\
34600 \\
39300 \\
37800 \\
37200\end{array}$ & $\begin{array}{l}49800 \\
39300 \\
44000 \\
45200 \\
43000\end{array}$ & $\begin{array}{l}50800 \\
44000 \\
48900 \\
47100 \\
41500\end{array}$ \\
\hline
\end{tabular}

TABLE V

The Early Crushing Strengths of Dental amalgams

Specimens $4 \times 8 \mathrm{~mm}$.-Normal mix and hand condensation-Compressed .003 inch per minute

\begin{tabular}{|c|c|c|c|c|c|c|}
\hline \multirow[t]{2}{*}{$\begin{array}{c}\text { AGE OF } \\
\text { SPECIMEN }\end{array}$} & \multicolumn{2}{|c|}{ ALLOY NO. 1} & \multicolumn{2}{|c|}{ ALLOY No. 3} & \multicolumn{2}{|c|}{ ALLOY NO. 4} \\
\hline & $\begin{array}{l}\text { (LBS. PER } \\
\text { SQUARE } \\
\text { INCH) }\end{array}$ & $\begin{array}{c}\text { (PER CENT } \\
7 \text {-DAY } \\
\text { STRENGTH) }\end{array}$ & $\begin{array}{l}\text { (LBS. PER } \\
\text { SQUARE } \\
\text { INCH) }\end{array}$ & $\begin{array}{c}\text { (PER CENT } \\
\text { 7-DAY } \\
\text { STRENGTH) }\end{array}$ & $\begin{array}{l}\text { (LBS. PER } \\
\text { SQUARE } \\
\text { INCH) }\end{array}$ & $\begin{array}{l}\text { (PER CENT } \\
7 \text {-DAY } \\
\text { STRENGTH) }\end{array}$ \\
\hline $\begin{array}{r}\text { Minutes } \\
20 \\
30\end{array}$ & $\begin{array}{l}2200 \\
2800\end{array}$ & $\begin{array}{l}6 \\
7\end{array}$ & $\begin{array}{l}2700 \\
2800\end{array}$ & $\begin{array}{l}7 \\
7\end{array}$ & $\begin{array}{l}2400 \\
3600\end{array}$ & $\begin{array}{r}6 \\
10\end{array}$ \\
\hline $\begin{array}{l}40 \\
50 \\
60\end{array}$ & $\begin{array}{l}3700 \\
5300 \\
5900\end{array}$ & $\begin{array}{r}9 \\
13 \\
15\end{array}$ & $\begin{array}{l}4000 \\
4700 \\
5400\end{array}$ & $\begin{array}{l}11 \\
12 \\
14\end{array}$ & $\begin{array}{l}4000 \\
4600 \\
6000\end{array}$ & $\begin{array}{l}11 \\
12 \\
16\end{array}$ \\
\hline $\begin{array}{l}70 \\
90\end{array}$ & $\begin{array}{r}8800 \\
11600\end{array}$ & $\begin{array}{l}22 \\
29\end{array}$ & $\begin{array}{l}5600 \\
7400\end{array}$ & $\begin{array}{l}14 \\
19\end{array}$ & $\begin{array}{l}6600 \\
7400\end{array}$ & $\begin{array}{l}17 \\
19\end{array}$ \\
\hline $\begin{array}{l}\text { Hours } \\
3\end{array}$ & $\begin{array}{l}18500 \\
26900 \\
37400\end{array}$ & $\begin{array}{l}47 \\
69 \\
95\end{array}$ & $\begin{array}{l}13000 \\
20600 \\
29200\end{array}$ & $\begin{array}{l}33 \\
52 \\
74\end{array}$ & $\begin{array}{l}13600 \\
18800 \\
27900\end{array}$ & $\begin{array}{l}37 \\
50 \\
74\end{array}$ \\
\hline Days & $\begin{array}{l}37100 \\
39500\end{array}$ & $\begin{array}{r}94 \\
100\end{array}$ & $\begin{array}{l}32900 \\
39300\end{array}$ & $\begin{array}{r}84 \\
100\end{array}$ & $\begin{array}{l}32900 \\
37800\end{array}$ & $\begin{array}{r}87 \\
100\end{array}$ \\
\hline
\end{tabular}


TABLE VI

Crushing Strengths of Dental Amalgams

$4 \times 8 \mathrm{~mm}$. specimens-Seven days old-Compressed .003 inch per minute

\begin{tabular}{l|l|c|c|c|c|c}
\hline $\begin{array}{c}\text { METHOD of } \\
\text { MIXING }\end{array}$ & $\begin{array}{c}\text { METHOD OF } \\
\text { CON- } \\
\text { DENSING }\end{array}$ & $\begin{array}{c}\text { ALLOY NO. 1 } \\
\text { (LBS. PER } \\
\text { SQUARE } \\
\text { INCH) }\end{array}$ & $\begin{array}{c}\text { ALLOY NO. 2 } \\
\text { (LBS. PER } \\
\text { SQUARE } \\
\text { INCH) }\end{array}$ & $\begin{array}{c}\text { ALLOY NO. 3 } \\
\text { (LBS. PER } \\
\text { SQUARE } \\
\text { INCH) }\end{array}$ & $\begin{array}{c}\text { ALLOY NO. 4 } \\
\text { (LBS. PER } \\
\text { SQUARE } \\
\text { INCH) }\end{array}$ & $\begin{array}{c}\text { ALLOY NO.5 } \\
\text { (IBS. PER } \\
\text { SQUARE } \\
\text { INCH) }\end{array}$ \\
\hline Mortar & Hand & 40500 & 33800 & 40500 & 38800 & 32600 \\
\hline Under mix & Hand & 40100 & 33100 & 38400 & 39900 & 36000 \\
\hline Normal & Hand & 39500 & 34600 & 39300 & 37800 & 37200 \\
\hline Over mix & Hand & 39600 & 35800 & 40900 & 38400 & 37400 \\
\hline Normal & A light & 38700 & 29700 & 38000 & 36700 & 37000 \\
Normal & A Medium & 39400 & 33800 & 41400 & 39400 & 35300 \\
Normal & A Heavy & 40500 & 35800 & 40800 & 36700 & 34800 \\
\hline Normal & B 1 & 35800 & 30300 & 36600 & 33600 & 28900 \\
Normal & B 2 & 39100 & 31600 & 39700 & 36700 & 34000 \\
Normal & B 3 & 39500 & 31800 & 40200 & 37200 & 35200 \\
\hline Normal & C 3 & 39500 & 35000 & 39100 & 36300 & 36000 \\
Normal & C 4 & 41900 & 35400 & 41900 & 36800 & 38900 \\
Normal & C 5 & 42000 & 35600 & 40100 & 37600 & 38700 \\
\hline Mortar & A Heavy & - & 32800 & 38300 & - & - \\
Mortar & B 3 & - & 32000 & 37000 & - & - \\
Mortar & C 5 & - & 31900 & 38900 & - & - \\
\hline
\end{tabular}

The modulus of elasticity was determined on the amalgam alloys studied by placing specimens $4 \mathrm{~mm}$. in diameter and $8 \mathrm{~mm}$. long in the Olsen testing machine and compressing them with the head speed regulated at 0.003 inch per minute. Deformation of the specimens was measured with a sensitive dial gage $(0.0001$ inch) attached to the platens. Strain was calculated over the entire length of the specimen and the stress in pounds per square inch determined on the original eross-section area of the specimens. The testing procedure was to apply a 25-lb. load (approximațely $1250 \mathrm{lbs}$./inch) and take a fiducial strain reading on the gage, then take subsequent readings at 50,100, 150, 200 , ete., pounds up to the maximum load while the strain was being. applied at a constant rate. It was observed that a maximum load would be reached and the beam would drop, showing that the specimens were flowing or shortening at a higher rate than the load was being applied. By keeping the load on the specimens balanced, it was possible to cause them to flow for considerable time without visible fracture, producing "beer-keg" shapes of greatly increased diameter in the mid-section and with correspondingly decreased length.

It is realized that the recording of measurements of strain made by observing the change in distance between the head platens of the machine is not in accordance with the best engineering practices. It would be better to measure strain on a gauged section some distance away from the ends, but no strain gauge was available for compressive specimens having a total length of $8 \mathrm{~mm}$. However, it was found that moduli computed from a stress of 5000 lbs. per square inch to $25,000 \mathrm{lbs}$. per square inch gave reproducible results. The individual values for any set of conditions used in making the specimens can be determined to within 10 per cent. The major error in the determination is caused by the use of such short gauge lengths. The average values for the moduli of elasticity are given in Table VII. They were ealculated for all of the specimens whose crushing strengths were reported in Table VI. 
TABLE VII

Modvles of Elasticity of Dental Amaigams

$t \times 8 \mathrm{~mm}$. specimens-Seven days old-Compression rate .003 inch per minute

\begin{tabular}{|c|c|c|}
\hline \multirow[b]{2}{*}{ AILLOY } & \multicolumn{2}{|c|}{ MODULUS OF ELASTICITY } \\
\hline & $\begin{array}{c}\text { RANGE } \\
\text { (IBS. PER SQCARE INCH) }\end{array}$ & $\begin{array}{c}\text { AVERAGE } \\
\text { (LBS. PER SQUARE INCH) }\end{array}$ \\
\hline 1 & 1.6 to $2.1 \times 10$ & $1.8 \times 10^{3}$ \\
\hline 2 & 1.2 to 1.7 & 1.4 \\
\hline 3 & 1.4 to 2.0 & 1.7 \\
\hline 4 & 1.4 to 1.8 & 1.6 \\
\hline 5 & 1.3 to 1.9 & 1.7 \\
\hline
\end{tabular}

DISCUSSION OF RESULTS

Specimen Size.-The $4 \times 8-\mathrm{mm}$. specimens tested showed somewhat greater erushing strengths than the $6 \times 12-\mathrm{mm}$. specimens. Under the slow load application used, it would appear that, for similarly proportioned samples, the ultimate strength recorded would vary inversely with the length of the specimens rather than being affected by relative cross sectional areas.

Compression Rate.-The head speeds used in this study were obtained by applying an auxiliary slow speed drive to an Olsen testing machine used with a 1000-pound range. The crushing strengths noted varied materially with the compression rate which, for the short samples studied, approximated closely the shortening of the specimens under load.

The .003-inch-per-minute compression rate was slow enough to make it possible to correlate head travel and load and so plot reproducible stress strain diagrams and determine with reasonable accuracy the modulus of elasticity of the specimens tested. Specimens showed a maximum resistance of stress followed by plastic flow at stresses lower than the maximum without showing fracture.

Typical stress strain curves are shown in Fig. 2. It will be noted that the point at which the elastic characteristies of the material are lost and plastic flow begins is well defined in the cross sectional stress-strain diagram (Curve $A$ ) and accentuated in Curve $B$ by plotting stress against rate of deformation.

Higher loading rates made it impossible to correlate load and head speeds. It was evident that the load applications were so rapid that the specimens could not flow as they did at the lower speed. The higher the speed, the greater was the tendency of the specimens to crack with explosive violence. It would appear that unstated or, perhaps, undetermined loading rates might well explain the variations in crushing strengths of the same alloys as reported by various manufacturers and investigators.

The .003-inch-per-minute head speed gave average crushing strength values 15 per cent lower than those by the 0.017 -inch speed and 19.5 per cent lower than the .024-inch speed. It is felt that the values obtained at the low speed would be far more indicative of the practical behavior of amalgams in dental service than those obtained from tests at higher or undefined head speeds, as they make possible the determination of the elastic characteristies of the amalgam. 
Early Crushing Strengths.-The early crushing strengths of dental amalgams are of prime importance as the early development of high crushing strength serves to minimize the possibility of the destruction of amalgam restorations through the premature application of load.

The series of specimens of Alloys Nos. 1, 3, and 4 were tested at ten-minute intervals from 20 to 70 minutes, at 90 minutes, at 3, 6, and 9 hours, and at 1 day and 7 days after trituration was begun. The data secured are given in Table V in the columns, "Pounds per Square Inch" and "Per Cent of the SevenDay Strength," the latter figure being of, perhaps, greater general usefulness, as it gives the dentist a relative idea of how long the patient should wait before masticating on the amalgam restoration.

The data on early strength are plotted against the age of the specimens in Fig. 3. The data on the percentage of seven-day strengths related to specified time intervals are shown in Fig. 4.

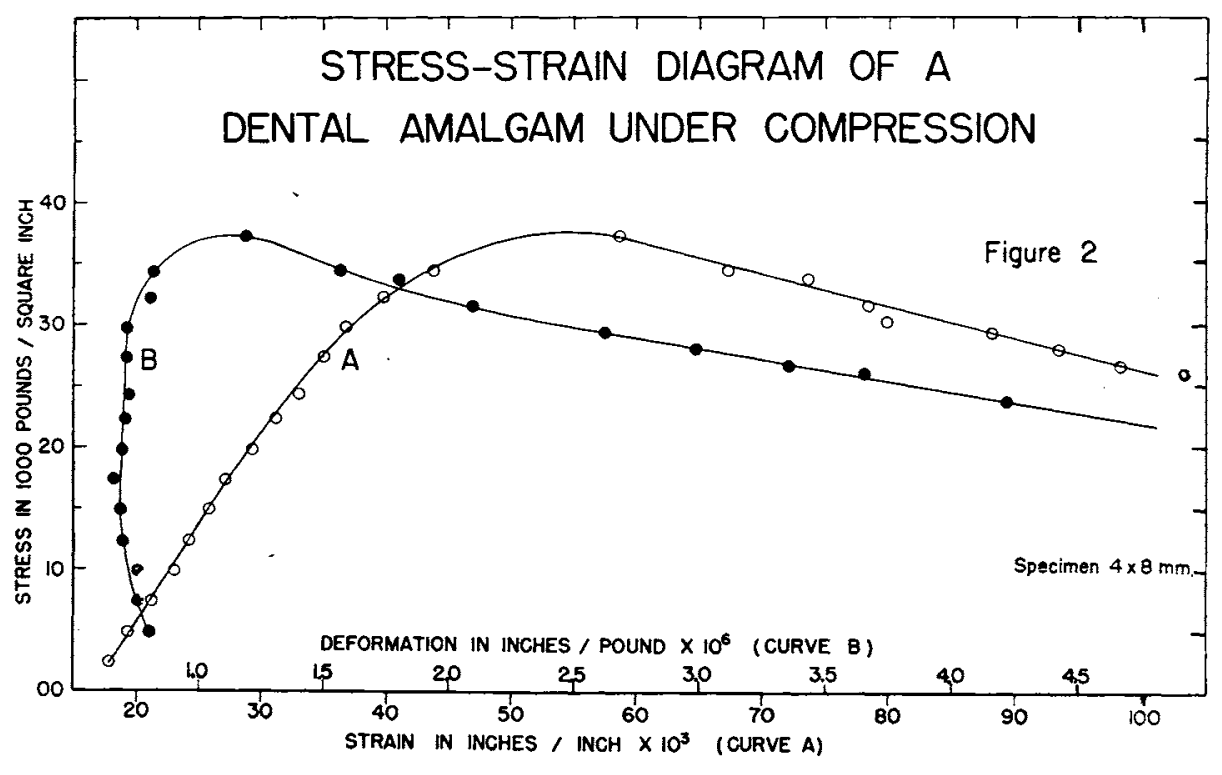

Fi3. 2.

The three alloys (Nos. 1, 3, and 4) showed average increases in crushing strengths of 98, 90, and 100 pounds per square inch per minute for the first hour, setting up uniformly but slowly. In the next thirty-minute period, Alloy No. 1 showed a greater inerease of strength than the others, the increases being respectively 190,66 , and $80 \mathrm{lbs}$. per square inch per minute. From ninety minutes the rates of increase in strengths were 74,62 , and 69 on the same basis. These results indicate that Alloy No, 1 would have an advantageous early strength in restorations subject to early stress.

In general, these tests for early crushing strength, though on only thrce alloys, appear to indicate that: (1) Mastication stresses of any sensible magnitude applied in less than one hour are dangerous to the success of amalgam 
restorations as less than one fifth of the maximum strength has been attained. (2) Six hours or more should elapse between packing and the application of stress to amalgams to provide at least 50 per cent of the maximum strength. (3) After nine hours some high grade amalgams will withstand all normal stresses while others may require twenty-four hours before their crushing strengths are entirely adequate.

It should be remembered that the data reviewed were obtained at room temperatures and that amalgams under mouth conditions might logically be expected to have both a somewhat faster rate of set and a lower maximum resistance to compression stresses.

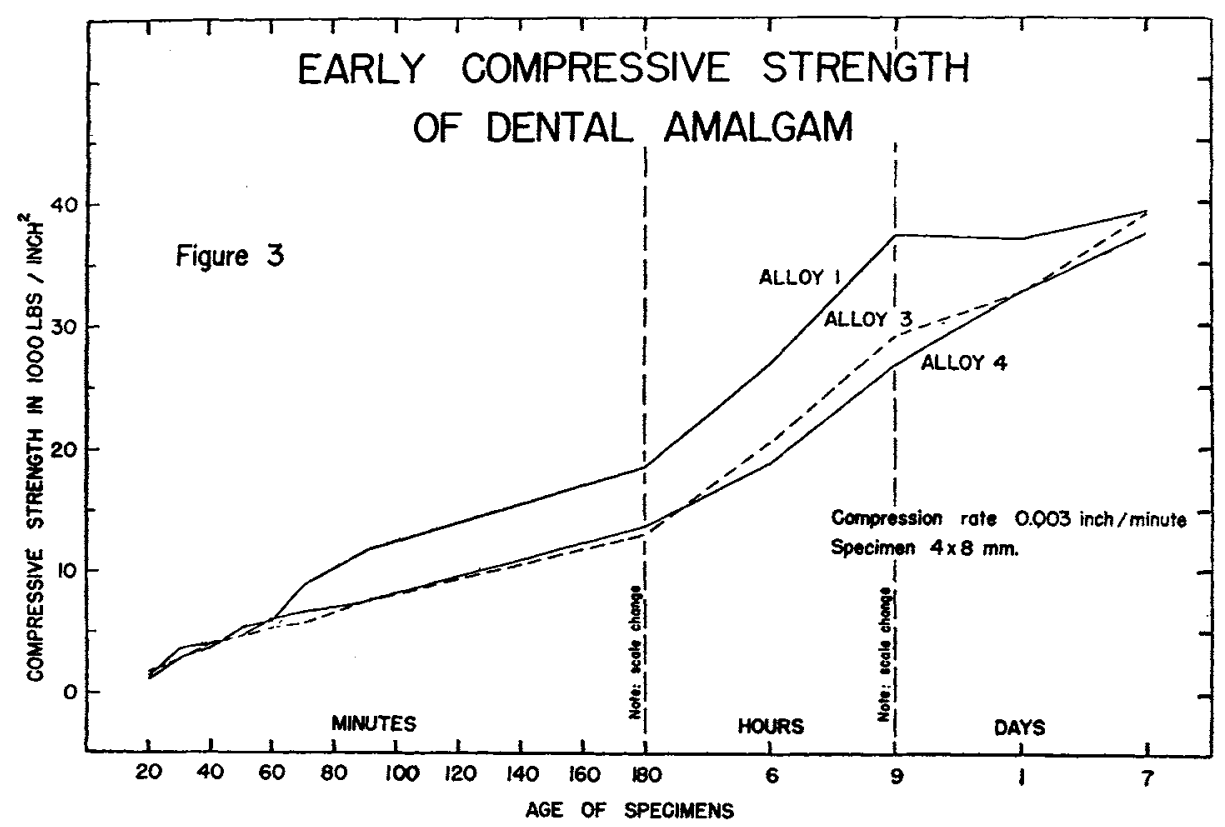

Fig. 3.

These data are also of particular interest in that they seem to correlate well with results obtained from the American Dental Association Specification No. 1 Flow Test. Flow values for the alloys studied showed that under a variety of conditions the average flow of Alloy No. 1 was 1.7 per cent, that of Alloy No. 3 was 3.2 per cent, while that of Alloy No. 4 was 5.9 per cent. The values for this last alloy were over the upper permissible limit of 4 per cent.

Alloy No. 1 showed relatively high crushing strength at the end of three hours, and this undoubtedly explains its low flow value. Alloys Nos. 3 and 4 have about equivalent strengths at the end of three hours, but the strength of Alloy No. 3 increases more rapidly during the following six hours and evidently results in a lower flow value.

Crushing tests at low speed can be carried out at intervals of approximately ten minutes. It would appear that such a test carried out at the end of a six- 
hour period might well be considered as a substitute for the present specification test for flow, which has the disadvantages of requiring a separate testing instrument for each sample, and in addition, a twenty-four hour period for completion of the test. Therefore, the method suggested would definitely facilitate the testing of large numbers of alloys as several samples could be tested daily on a single machine.

Seven-day Compression Tests.-Tests were made to determine the effects of several methods of mixing and condensing amalgams on their erushing strengths.

Mechanical amalgamators are seldom, if ever, sold with adequate instruetions for mixing current amalgam alloys. This renders their use in practice dangerous unless careful consideration is given to their proper control. In general it appears that users are not familiar with the wide variations in the amalgamating time of current alloys nor of the variable characteristies of the amalgamators, and so normal and undermixing and overmixing by mechanical means were included in this study.

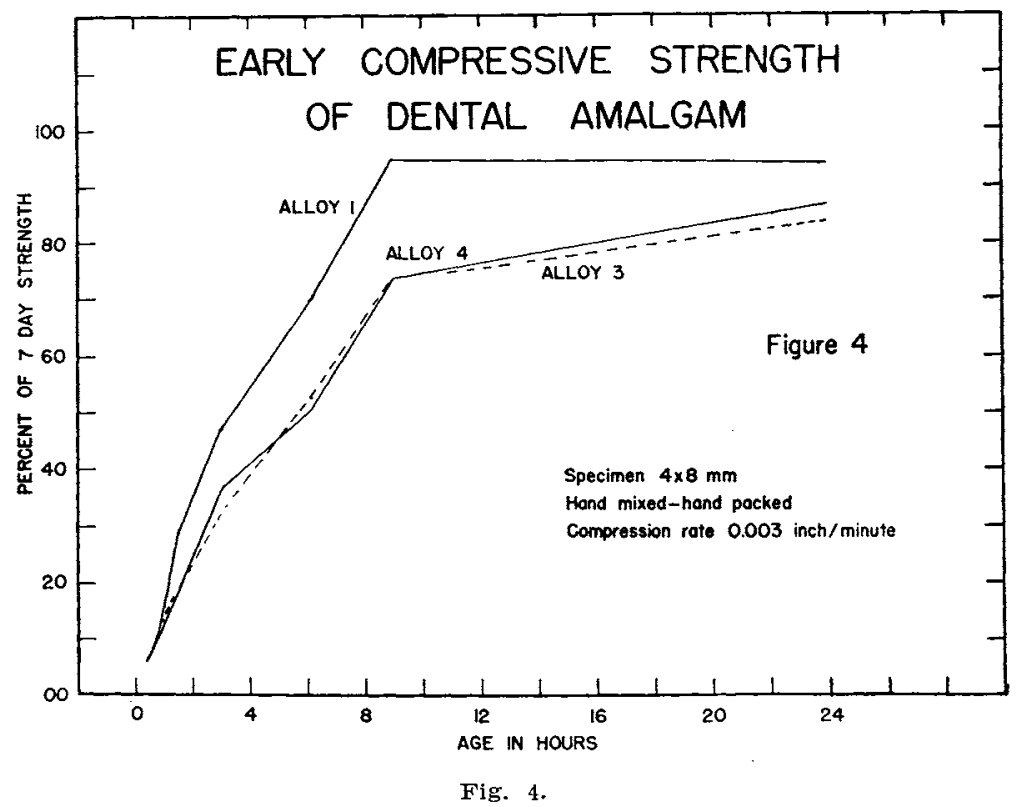

Current increased interest in mechanical condensors was the basis for the inclusion of these instruments in the investigation and those selected for study covered the avaitable mechanical types. This type of instrument has most often been sold on the basis of generalized claims unsupported by data on its effects upon the properties of amalgams, but emphasizing the convenience of its use. There has also been a marked tendency to stress mereury removal without consideration of its possible detrimental effects upon the expansion of amalgams.

It is obvious that both types of instruments may have practical advantages for use in dental practice which laboratory tests do not take into consideration. 
As the data reported here were secured strictly on a laboratory basis, no attempt has been made to evaluate the possible convenience values of either amalgamators or condensors.

Careful consideration of the data secured on the effects of variations in mixing and condensation indicates that an operator may expect no great improvements in the strength of his amalgam restorations as the result of his use of mechanical devices and that, conversely, if the instruments are improperly controlled, he may expect inferior results.

There appeared to be one set of operating conditions for each condensor which gave best results. Condensor $A$ gave poor and erratic results at low pressures and its most consistent results when operated at intermediate pressures. Condensor B gave very poor results at slow speeds and less satisfactory results than the other instruments when operated at higher speeds although its performance showed some improvement. Most consistent results were obtained with Condensor $\mathrm{C}$ operated at its highest speed, but then only after sufficient warm-up time was allowed for its speed to become stabilized.

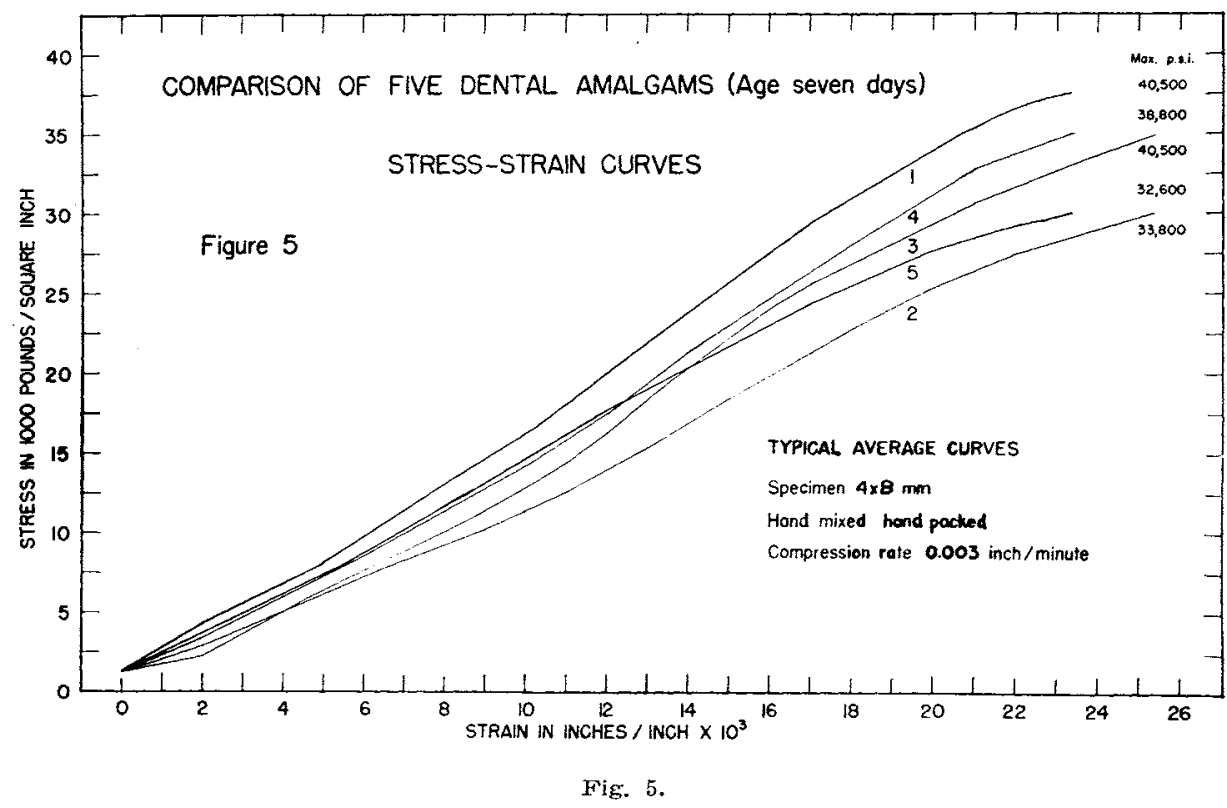

Visual observation of the hundreds of specimens included in this study warrant an opinion that mortar-mixed alloys, having been exposed to the penetration of mercury for longer periods, have somewhat better packing characteristics than mechanically triturated materials. This was borne out by an apparent greater uniformity of mortar-mixed samples as shown by the data on individual alloys, but these better packing characteristics were not directly associated with greater strengths.

Visual observation of the specimens packed by mechanical means indicate a greater tendency toward lamination with resultant possibilities of separation 
of layers under light stress especially in the time intervals just following packing. This was particularly true if the specimens were dried out by the removal of mercury from each addition of alloy to a point where the surfaces showed no free mercury.

Typical average stress-strain curves for the five alloys studied are shown in Fig. 5.

Modulus of Elasticity.--The modulus of elasticity as determined by the tests described gave average values of $1.6 \pm 0.2$ million pounds per square inch for the five alloys tested. The method of preparation of the specimens had some effect on the value of the modulus. The higher the ultimate compressive strength, in general the higher the modulus value. This did not seem to hold for all the individual combinations of specimen preparations and possibly is connected with the amount of mercury left in the test specimen.

The fact that the modulus of elasticity of amalgam alloys is low may be an important cause of failure in service. The following list of moduli of elasticity of a few common materials will show how this property of amalgams compares with those of other materials. It should be observed that the modulus of amalgam appears very low in comparison with its ultimate compressive strength and high deformation per unit stress must be expected.

TABLE VIII

\begin{tabular}{l|c}
\hline \multicolumn{1}{c}{ Material } & $\begin{array}{c}\text { MoDULUS OF ELASTICITY } \\
\text { (I.BS. PER SQUARE INCH) }\end{array}$ \\
\hline Copper & $16.0 \times 10^{6}$ \\
Dental Casting Gold & 14.0 \\
Aluminum & 11.3 \\
Gold & 11.3 \\
Magnesium & 6.2 \\
Lead & 2.6 \\
Amalgam (Dental) & 1.6 \\
Poly-Methyl Methacrylate & 0.4 \\
\hline
\end{tabular}

The modulus of elasticity is an index to the stiffness of a structural material so it would be expected that any thin edge in an amalgam filling would be very susceptible to breaking or chipping. It should be pointed out that the cavity preparation for amalgam should be such that all very thin sections which may be subjected to stress should be eliminated. Amalgam will not absorb much energy quickly without fracture, but the slow application of relatively high loads will not cause fracture although permanent deformation must be expected. It would seem desirable to investigate the relation of this property to clinical use.

The stress-strain diagrams and data obtained from the various crushing strength tests were considered to decide whether it was feasible to attempt the determination of proportional limits of amalgams. The shapes of the curves indicated that the accurate determination of this property would be difficult because of the gradually increasing rates of strain to stress. However, proportional limits were estimated by observing the stress necessary to increase the strain increment per unit of stress to 1.25 times that of its average value between 5,000 and 25,000 pounds per square inch. 
The observed values were generally between 70 and 80 per cent of the ultimate compressive strengths. The inherent flow of amalgams, especially under high stress, affects the values of proportional limit, and it is felt that they do not serve as a reliable index of the serviceability of the alloys.

\section{CONCLUSIONS}

The conclusions which appear logical from consideration of the data secured in this study and of the requirements of dental amalgams in service are:

1. Crushing strengths of dental amalgams should be determined on specimens made from mixes approximating in size those commonly made by dentists. Approximately 12 grains of alloy and an appropriate amount of mercury will provide sufficient material to pack a $4 \times 8$-mm. test cylinder.

2. The smaller $4 \times 8$-mm. specimens used gave a 2 to 7 per cent increase in erushing strength over that of the $6 \times 12-\mathrm{mm}$. cylinders used by previous investigators when prepared and tested under the same conditions.

3. The compression rate should be given in reporting erushing strengths of dental amalgams to permit reproduction of test data. It appears that such speeds should be standardized at approximately 0.003 inch per minute to determine both the elastic and plastic properties of amalgams.

4. The early strengths of amalgams are so low that no stress should be applied to a restoration less than an hour old, and any mastication of food on occlusal amalgam restorations less than six hours old may be expected to cause damage.

5. The compressive strengths of the five alloys studied were determined under thirteen different combinations of mixing and packing procedures. The variations in crushing strengths among these alloys were greater than those produced in the individual amalgams by varying technics.

6. The wide variation in the rates of amalgamation of the current amalgam alloys under mechanical trituration indicates that the user of such mechanical devices needs exact directions for mixing of the specific alloy used if he is to avoid all possibility of unsatisfactory physical properties in finished restorations.

7. Laboratory data indicated no significant improvement in the crushing strengths of amalgams as the result of mechanical rather than hand condensation. As previously mentioned, convenience may be a factor deserving of consideration from the clinical viewpoint.

8. The moduli of elasticity of the five amalgam alloys studied were within the range 1.2 to $2.1 \times 10^{6}$ pounds per square inch. The average modulus for the alloys studied was $1.6 \times 10^{6}$ pounds per square inch. This value is very low in comparison to those of the other alloys used as restorative dental materials. The clinical significance of this property warrants further study.

9. The proportional limits of the amalgams studied varied with mixing and condensing technies but fell within a range from 70 to 80 per cent of the crushing strengths observed when taken to be that stress at which the unit of deformation per unit stress exceeds the average value found in the range 5,000 to 25,000 pounds per square inch by more than 25 per cent. 
10. An early compressive strength test appears to be a significant and acceptable substitute for the present specification test for flow.

11. Compression testing of amalgam in the dental materials field has resulted in a dispersion of values because of the difference in the size of specimens and the types of testing machines used. In order to confine these varying conditions of test it would seem feasible to prescribe the rate of loading, expressed in pounds per square inch per minute, to which the specimen has been subjected. Using these units for rate of loading it would not be necessary to imagine what the effect on strength would be, of the length, or the area of the specimen; or whether the specimen was loaded at so many pounds per minute or so many inches per minute. Rate of loading in pounds per square inch per minute virtually absorbs all these variables. On this basis, Table IX was computed for the results outlined in this paper using data on Alloy No. 4.

TABISE IX

\begin{tabular}{|c|c|c|c|}
\hline $\begin{array}{l}\text { SPECIMEN SIZE } \\
\text { (MM.) }\end{array}$ & $\begin{array}{l}\text { HEAD SPEED TRAVEI, } \\
\text { (INCH PER MINLTE) }\end{array}$ & $\begin{array}{l}\text { LOADING RATE } \\
\text { (LBS. PER SQLAFE } \\
\text { INCH PER MINUTE) }\end{array}$ & $\begin{array}{c}\text { STRENGTH } \\
\text { (IABS. I'ER SQUARF, } \\
\text { INCH) }\end{array}$ \\
\hline $6 \times 12$ & 0.003 & 9,540 & 35,300 \\
\hline $4 \times 8$ & .003 & 15,250 & 37,800 \\
\hline $4 \times 8$ & .017 & 86,300 & 45,200 \\
\hline $4 \times 8$ & .024 & 122,000 & 47,100 \\
\hline
\end{tabular}

\section{REFERENCES}

1. Ward, M. L., and Scott, E. A.: J. A. D. A. 19: 1083, 1932.

2. Phillips, R. W.: J. A. D. A. 31: 1308, 1944.

3. Phillips, R. W., and Boyd, D. A.: J. A. D. A. 34: 451, 1947. 